\title{
Implementation of an electronic Objective Structured Clinical Exam for assessing practical skills in pre-professional physiotherapy and occupational therapy programs: Examiner and course coordinator perspectives
}

\author{
Suzanne J. Snodgrass, Samantha E. Ashby, and Darren A. Rivett \\ School of Health Sciences, The University of Newcastle, Australia \\ Trevor Russell \\ School of Health and Rehabilitation Sciences, The University of Queensland, Australia
}

\begin{abstract}
Assessment of practical clinical skills is essential in the health fields. Objective Structured Clinical Exams (OSCEs), where examiners assess students performing clinical procedures on simulated patients (actors), are central to the evaluation of practical skills. However, traditional OSCEs require considerable time-investment to administer, and providing timely, individualised student feedback is difficult. To address these issues, an electronic OSCE (eOSCE) was developed utilising the iPad and specialised software. The eOSCE was trialled in four courses within two entry-level rehabilitative pre-professional programs at two universities, physiotherapy and occupational therapy. Evaluation consisted of student surveys $(n=206)$, eight student focus groups $(n=25)$, examiner surveys $(n=25)$ and interviews with course coordinators $(n=3)$. This paper describes the administration of the eOSCE and reports on its evaluation from the academic's perspective. A majority of examiners $(68 \%)$ preferred the eOSCE over traditional paper-based OSCEs, primarily because of the consistency and promptness of student feedback. The advantages academics cited were equitable student feedback and post-examination administrative time-savings. Disadvantages of the eOSCE were the pre-examination preparation required and challenges for examiners not comfortable using technology. Overall, the key benefits of the eOSCE were the automated, immediate individualised student feedback and a time saving in OSCE administration.
\end{abstract}

\section{Introduction}

Objective Structured Clinical Exams (OSCEs) have been used worldwide to evaluate the clinical skills of students in the medical and allied health professions (Fields, Rowland, Vig, \& Huja, 2007; McIlroy, 2000; Ross, Carroll, Knight, Chamberlain, Fothergill-Bourbonnais, \& Linton, 1988; Sturpe, 2010; van den Berk, van de Ridder, \& van Schaik, 2011). Traditional OSCEs involve examiners evaluating and scoring the performance of students on paper as they perform clinical procedures on simulated patients or actors. Typically, a student performs different clinical procedures across a series of "stations", with each marked by a different examiner. This method enables examiners to evaluate students performing a broad range of practical skills. However, with large numbers of students and limited time for observing and scoring student performance at each station, there is little opportunity for examiners to provide timely, individualised feedback. Thus, when students receive feedback from OSCEs it is often delayed, resulting in student dissatisfaction, (Turner \& Dankoski, 2008) with a negative impact on student learning. In addition, the reliability of assessment may vary between examiners, with additional potential errors when data are transferred from paper to digital mediums for collating student marks (Rushforth, 2007; Turner \& Dankoski, 2008; Wilkinson, Frampton, Thompson-Fawcett, \& Egan, 2003). Importantly, conventional OSCE methods are highly resource intensive for educators (Hawker, Walker, Barrington, \& Andrianopoulos, 2010), and become increasingly challenging to administer with larger cohorts of students. Critical shortages of health professionals worldwide (Bhatt, Giri, \& Koirala, 2010; Health Workforce Australia, 2011) highlight the need to educate more students. Therefore, there is a need to develop more efficient and effective methods for evaluating students' practical clinical skills.

Improved examination efficiency and timely individualised student feedback can potentially be achieved using a computerised or electronic marking system to assist in the evaluation practical skills. The advent of the iPad provides a new mobile electronic medium that examiners can use as they move around the student to assess practical skills. Using an electronic medium allows examiners to record their comments 
directly, minimising the potential errors and post-examination workload associated with transferring marks into electronic files. Additionally, students can be provided with feedback directly and immediately from each OSCE examiner. Evidence from several studies indicates that electronic marking systems utilising personal digital assistants (PDAs) are effective and preferred by educators for examining medical students (Nackman, Griggs, \& Galt, 2006; Schmidts, 2000; Treadwell, 2006; Yuen \& Yuen, 2003). However, there were no identified studies evaluating the use of an electronic examination of practical skills for allied health students. Furthermore, while an iPad may potentially provide a more user-friendly medium for the examiner than the PDA (as its screen is larger), there were no identified published reports of using the iPad in the assessment of practical skills. This paper describes the implementation and evaluation of an electronic OSCE (eOSCE) using the iPad to assist in evaluating physiotherapy and occupational therapy students at two universities in Australia.

\section{Methods}

\section{Implementation of the eOSCE}

The project was a collaboration between a medium-sized regional university, The University of Newcastle (UoN) and a large metropolitan university, The University of Queensland (UQ), in Australia. The eOSCE was implemented in two disciplines, physiotherapy and occupational therapy. This was done to increase the generalisability of the results to allied health disciplines across the university sector. The eOSCE was used with students in the second year of their professional entry-level programs at both universities. It was implemented in one of their university courses (also called university subjects) which included instructional content related to practical clinical skills. The students' study for these courses comprised approximately one quarter of a student's coursework within a single academic term. At the UQ, both undergraduate and graduate-entry Masters students in physiotherapy participated in an eOSCE within their respective university courses. At the UoN, undergraduate students in both physiotherapy and occupational therapy participated in an eOSCE within their respective university courses. The content of the eOSCE was specific to the individual university courses $(n=4)$ for each of the groups of students described above. However, the use of the eOSCE system was standardised. In each course, examiners used the same proprietary software (Mark-Rite ${ }^{\mathrm{TM}}$, Clarity Data Solutions, Brisbane QLD, Australia) to administer the eOSCEs.

Each university course (one physiotherapy course at the UoN, one occupational therapy course at the UoN, and one undergraduate and one graduate-entry Masters physiotherapy course at the UQ) was managed by a course coordinator. The course coordinators were responsible for designing the practical skills assessment tasks and marking criteria, organising the exam, and communicating results to students. Three educators acted as course coordinators: At the UQ, one educator coordinated both of the two courses involved in this study, whereas at the UoN there was a different coordinator for each of the two courses. Two eOSCEs were administered within each of these courses: a mid-semester and an end of semester examination. Therefore all students participated in two eOSCEs. The percentage of the overall assessment grade allocated to the eOSCE within each course was at the discretion of the individual course coordinators. All eOSCEs utilised a "station" based exam, where students were examined performing various practical skills at different stations, each evaluated by a different examiner. The eOSCEs were required examinations within the students' courses (with the exception of the mid-semester occupational therapy eOSCE at the UoN) and examiners were paid to attend training and examination days. However, participation in the evaluation of the eOSCE process was voluntary for students, examiners and course coordinators. Ethical approval for this study was obtained from Human Research Ethics Committees at both universities.

\section{The eOSCE system}

The eOSCE is designed to be used for examinations where students perform practical skills that are examined by multiple examiners, each examining one skill at a particular station. With the eOSCE, an examiner uses the iPad to enter marks and comments about a student's performance at a particular station. Information entered on the iPad is immediately sent to a server, which saves the data. The software (Mark-Rite ${ }^{\mathrm{TM}}$ ) then organises the data so that examiner comments can be sent to a student as feedback, and marks are collated in an Excel (Microsoft Corporation, Redmond WA, USA) spreadsheet for course coordinators to review before releasing to students using standard mechanisms such as Blackboard 
(Blackboard, Inc., Washington DC, USA). As the eOSCE is administered via a server using proprietary software (Mark-Rite ${ }^{\mathrm{TM}}$ ), there are no applications required for the iPad and there are no data stored on the iPads used for examining. This provides a level of data security for student information in case an iPad is left unattended and is inappropriately accessed, or is lost, either physically or via electronic malfunction. Examiners log into the server using their iPads in order to enter marks, and a course coordinator logs in via their desktop computer prior to an eOSCE in order to create an examination in the system. For eOSCEs in the current study, first and second generation iPads were used (iPad 1 and iPad 2, Apple, Inc., Cupertino CA, USA).

The proprietary software has two interfaces: one used by course coordinators to set up their examination and one used by examiners to mark the students. Prior to an eOSCE, a "superuser" uploads the course and student details into the system. This is done by entering the course details and then uploading student details using a compatible Excel spreadsheet that includes students' first and last names, their student numbers and their email addresses. Student email addresses are used to send their individualised feedback following an eOSCE. The course coordinator logs into the Mark-Rite ${ }^{\mathrm{TM}}$ system to design their eOSCE content, which is then viewed on the iPad by the multiple examiners who will be examining the students.

Examinations are organised by "Stations" and "Items", and each Item has "Criteria", "Feedback statements" and "Qualifier groups". A Station represents a location in a practical exam where a student is examined, usually marked by a single examiner who marks every student in the class. An Item is an exam question or skill that the student is required to perform. A Station can have any number of Items. Criteria are competencies that the student is required to achieve during the exam. An Item can have any number of Criteria. Criteria are marked on a numerical scale to create a mark for the student, or can also have binary outcomes, such as Pass/Fail if needed. Criteria are given a weighted percentage of the overall mark for the Item at the discretion of the academic designing the examination for the class. Each Criterion has a series of Feedback statements, which are common comments given to students about their performance on that particular Item. Feedback statements are pre-programmed into the system by the academic designing the examination, so that examiners can quickly select standardised Feedback statements during the eOSCE. Feedback statements have the option of having a Qualifier group to describe the student's performance related to the particular Feedback statement. For example, a Feedback statement might be "verbal and non-verbal communication with the client," and its Qualifier group "N/A, Substandard, Basic, Satisfactory, Good, Excellent." If an examiner wishes to provide the student with feedback about their verbal and non-verbal communication, they do this by selecting one of the descriptive words from the Qualifier group. If no descriptor is selected from the Qualifier group, then the student does not receive that particular Feedback statement as part of their feedback for their examination. An example of a single Criterion for an eOSCE Item, as viewed by the examiner, is provided in Figure 1. Figure 2 depicts the same Criterion, as it appears to the student when they receive feedback on that Criterion. Examiners also have the option of typing in free text into an open text box for more specific individualised student feedback.

When marking a student during an eOSCE, the examiner first selects the student's name, which has been pre-loaded into the system prior to the examination. They can also select the particular Item for that student's exam. Both of these are then 'locked' by clicking on a lock button. Each Criterion can also be locked after marking. This ensures that marks completed remain accurately in the system during scrolling to other parts of the examination. Following an eOSCE, an individual student's feedback can be sent to them either immediately, or at a time at the discretion of the course coordinator. Student feedback sent from the Mark-Rite ${ }^{\mathrm{TM}}$ system consists only of the Feedback statements, which are organised by Station and Item. The examiners' marks or scores for each Criterion and Item are organised by student into an Excel spreadsheet which the course coordinator can download. Course coordinators can request detailed scores on each Criterion and each Item, or can download a summary of scores from each Station in a single eOSCE. Course coordinators can then review marks before they are sent to students via official university systems, such as Blackboard. Security is ensured as each course coordinator and examiner has their own $\log$ in to Mark-Rite ${ }^{\mathrm{TM}}$, and individuals have different levels of access specific to the examination in which they are involved. Prior to the implementation of eOSCEs, all course coordinators and examiners attended training in how to use the system. 


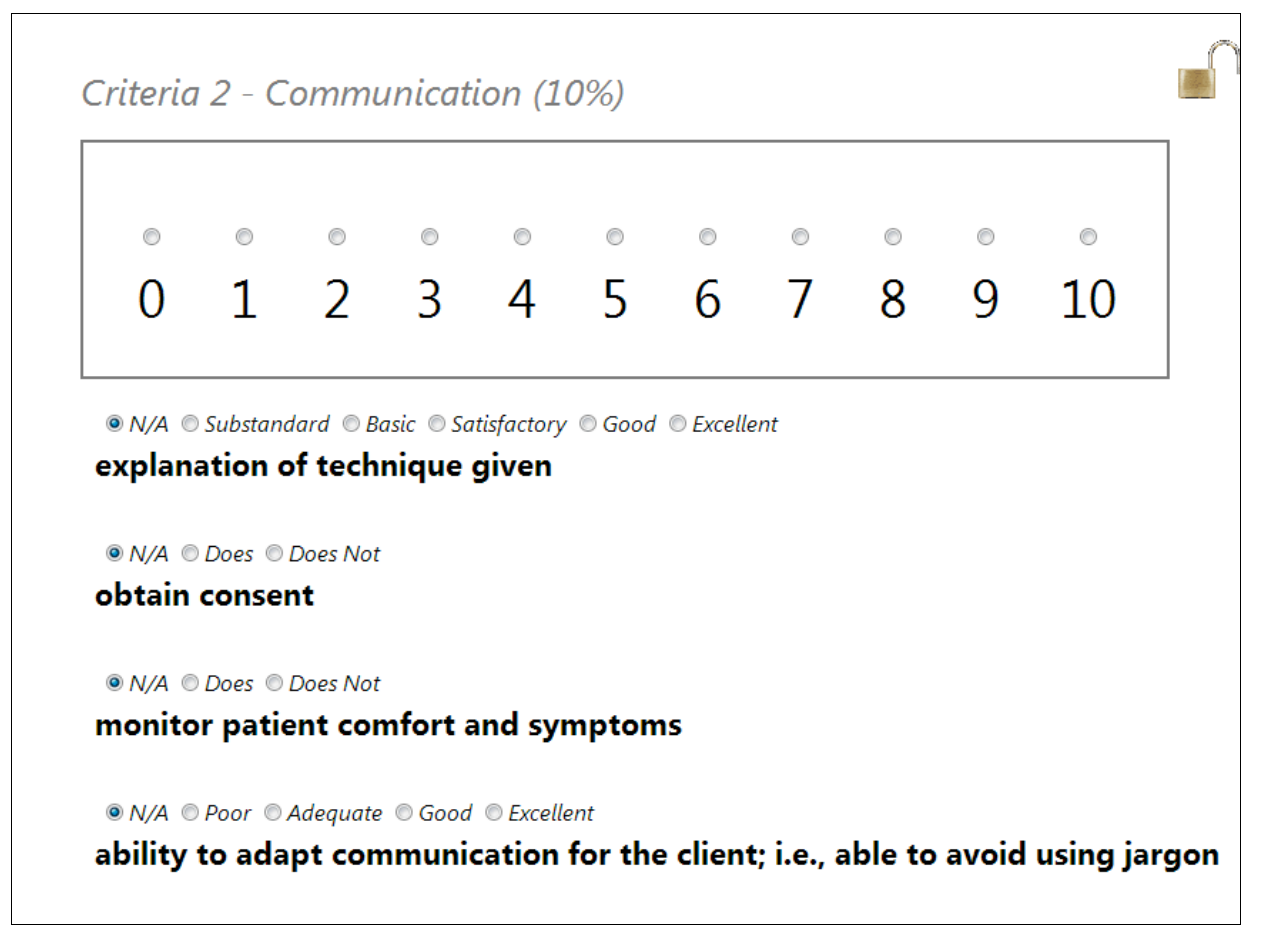

Figure 1. Example of a single eOSCE Criterion, as viewed by an examiner marking a student

\section{Evaluation of the eOSCE}

The eOSCE was formally evaluated using surveys of examiners and students, focus groups of students, and course coordinator interviews and logbooks. Logbooks were completed by course coordinators to determine the amount of time that they spent administering the eOSCE, as compared to previous pen-andpaper OSCEs. This paper will discuss the eOSCE from the academic's perspective in the context of the student response. Academics working closely with students received informal student feedback about this new examination method, which potentially influenced their responses in their surveys and interviews. This paper reports the results of the examiner surveys and course coordinator interviews and logbooks.

Dear Student A,
Course Name: PHTY4111
Exam Name: Lower Limb
Year: 2013
The following are the feedback statements which relate to your performance on the following stations / items
Station: Lower Limb
Item: Prac Viva A
Communication
Good explanation of technique given
Does obtain consent
Does Not monitor patient comfort and symptoms
Adequate ability to adapt communication for the client; i.e., able to avoid using jargon

Figure 2. Example of feedback received by a student for a single eOSCE Criterion 


\section{Examiner surveys}

Examiners were invited to complete a questionnaire after they had completed marking an eOSCE. The questionnaire was designed by the authors and piloted with a multidisciplinary panel of expert academics with collective experience in assessing students' practical clinical skills as well as questionnaire and research design. The questionnaire was modified after this consultation to include two additional items regarding examiner experience, and also additional space to encourage free-text comments. Examiner participation in the survey was voluntary and respondents remained anonymous.

Examiner questionnaires included three questions which evaluated their experience and satisfaction with the eOSCE system. Using a Likert scale with five levels ranging from 1 (Strongly disagree) to 5 (Strongly agree), examiners were asked if they found the eOSCE system easy to use, if it improved the quality of feedback they gave students, and if they preferred it over a paper-based OSCE. They were also requested to provide open-ended comments to support their selection to the Likert scale questions. They were then asked a series of three open-ended questions which included commenting on any advantages or disadvantages of the eOSCE, and any recommendations for future examiners. To address the possible confounder of examiner experience, they were asked to identify the number of previous OSCEs they had examined, as well as any previous experience with the eOSCE. Finally, they were given the opportunity to include any further open-ended comments about the eOSCE. The questionnaire was purposefully brief to encourage completion by examiners after a day of examining students. Some examiners marked both the mid-semester and final eOSCE for a student group, and they were invited to complete the survey after both eOSCEs in order to capture any differing views as a result of further experience with the eOSCE.

\section{Course coordinator interviews and logbooks}

An independent research assistant interviewed course coordinators for each course in which the eOSCE was administered. This included a physiotherapy lecturer and an occupational therapy lecturer at UoN and a single physiotherapy lecturer at UQ who coordinated both the undergraduate and graduate courses in which the eOSCE was administered. Interviews were structured around a series of questions that had been developed with the input of a multidisciplinary panel with expertise in teaching and learning in health. The panel included individuals from both the academic and clinical teaching areas. Course coordinators were asked to comment on the time needed to administer an eOSCE compared to a traditional paperbased OSCE, how the quality of student feedback compared with traditional methods, and whether they perceived the eOSCE to be more reliable than traditional methods. They were asked how satisfied they were with the eOSCE and whether they would choose it over a paper-based OSCE. They were then asked to comment on whether their experience with the mid-semester eOSCE made it easier to use at the final semester eOSCE, and any recommendations for other course coordinators administering an eOSCE. Finally, they were asked for their perceptions of how their examiners managed using the eOSCE system and how it impacted on their workload. Interviews were allowed to include other discussion as directed by individual course coordinators, but the structured questions formed a guide. Interviews were transcribed and the major themes across all coordinators were identified by an independent research assistant and one of the authors (S.S.) with consensus reached by discussion.

Course coordinators were also asked to complete a logbook to record the estimated time they spent performing various tasks while administering the eOSCE. They were asked to document and describe those specific tasks related to the administration of the eOSCE, such as designing the examination, collating marks or providing student feedback.

\section{Data analysis}

From the examiner surveys, responses from the Likert scale questions were analysed using descriptive statistics. A content analysis identified codes from the open-ended responses, which were then organised into common themes (Saldana, 2009). The two course coordinator interviews were transcribed and analysed by two of the researchers who each summarised the points discussed. The data from these course coordinator interviews are compared and contrasted in this paper. Data from returned course coordinator logbooks are reported descriptively. 


\section{Results}

\section{Examiner surveys}

A total of 25 examiner questionnaires were completed and returned after mid-semester and end of semester eOSCEs for an overall response rate of $74 \%$. Only five questionnaires were completed by examiners who had previous experience in marking an eOSCE. As questionnaires were anonymous, it is unknown whether these five questionnaires were completed by examiners who had already completed questionnaires when they participated in their first eOSCE. However, because there were no substantial differences in the proportions of positive and negative responses in these five questionnaires as compared to the other 20 questionnaires, all data was pooled for reporting.

All examiners except one reported that they had past experience examining students in a traditional OSCE format, with more than half $(56 \%)$ indicating they had examined previously in greater than 6 traditional OSCEs (though six questionnaires, or $24 \%$, were missing data on this question). Table 1 provides a breakdown of the composition of examiners in terms of their university location, their professional discipline and their previous OSCE and eOSCE examining experience.

Table 1

Description of examiners from returned questionnaires following the use of the iPad as an assessment tool in an eOSCE

\begin{tabular}{lcc}
\hline Descriptor & Number $(\mathrm{n})$ & Percent $(\%)$ \\
\hline Physiotherapy discipline & 21 & 81 \\
Occupational therapy discipline & 4 & 16 \\
University of Newcastle & 13 & 52 \\
University of Queensland & 12 & 48 \\
Previous experience examining an OSCE* & & 20 \\
$\leq 6$ prior OSCEs & 5 & 24 \\
$7-10$ prior OSCEs & 6 & 32 \\
$\geq 11$ prior OSCEs & 8 & 20 \\
Previous experience examining an eOSCE* & 5 & \\
*OSCE = Objective Structured Clinical Examination; eOSCE = electronic Objective Structured Clinical Examination
\end{tabular}

In each course where the eOSCE was administered, course coordinators participated as examiners but they were not asked to complete an examiner questionnaire, as they were subsequently interviewed about their experiences. As the number of examiners surveyed was small, data from both universities and health disciplines were combined to maintain the anonymity of participants.

Examiner responses to the Likert scale questions are illustrated in Figures 3-5. Most responding examiners $(84 \%, n=21)$ agreed or strongly agreed that the eOSCE system was easy to use (Figure 3), and two-thirds of examiners $(68 \%, \mathrm{n}=17)$ agreed or strongly agreed they preferred it over a paper-based system (Figure 4). Responses were mixed about whether the eOSCE system improved the quality of feedback they gave students, with the most common response being 'neutral' $(32 \%, \mathrm{n}=8)$ and almost equal numbers of responses that agreed or strongly agreed $(36 \%, n=9)$ and disagreed or strongly disagreed $(32 \%, \mathrm{n}=8$, Figure 5).

Only one examiner reported difficulties with using the eOSCE system: "I struggled to get the system to register what I wanted but got better with time". It was unclear exactly what the problem was but from their response it seemed to have been resolved during the course of the examination period. There was one instance where an examiner selected the wrong student, affecting the feedback sent to two students. This occurred where two students had the same last name, and two examiners were examining the same station (each examining half the student cohort). This was remedied by downloading the correct feedback from the online system and sending it to the students. It was discovered it could be prevented in future examinations by using a single station in the eOSCE system for both examiners, as the eOSCE does not allow selection of a student more than once at a single station. 


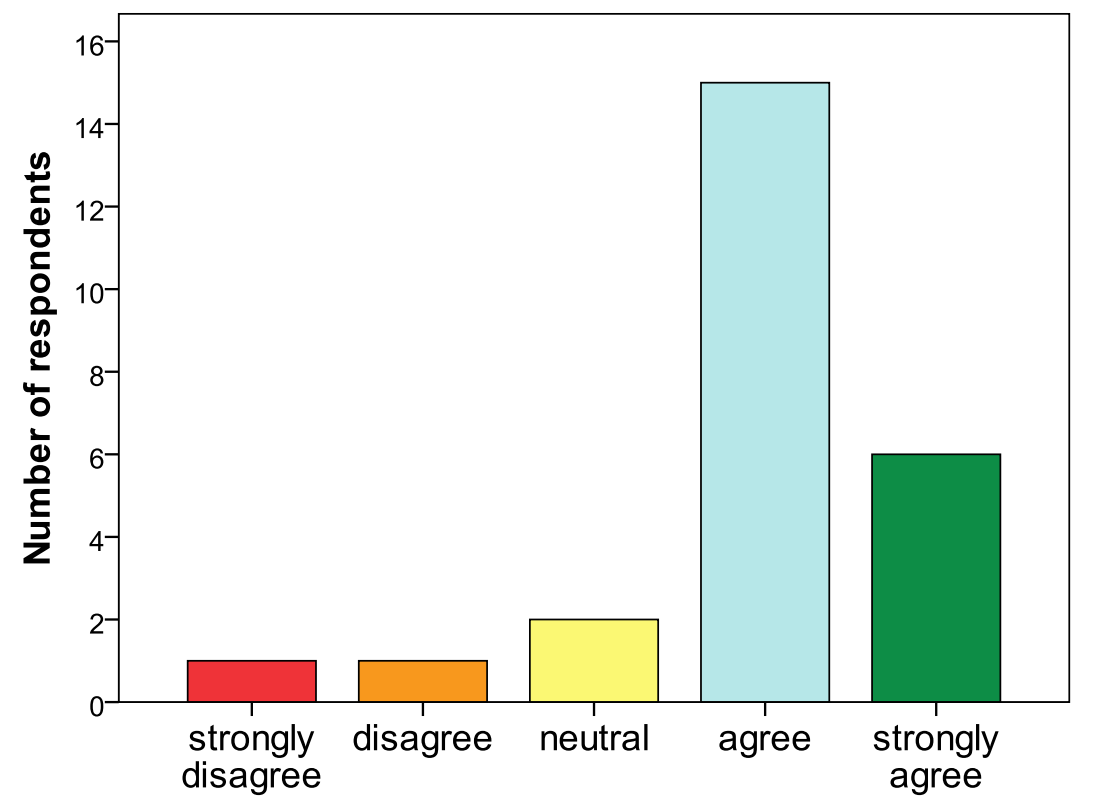

I found the eOSCE easy to use.

Figure 3. Examiner $(\mathrm{n}=25)$ response about the ease of use of the eOSCE

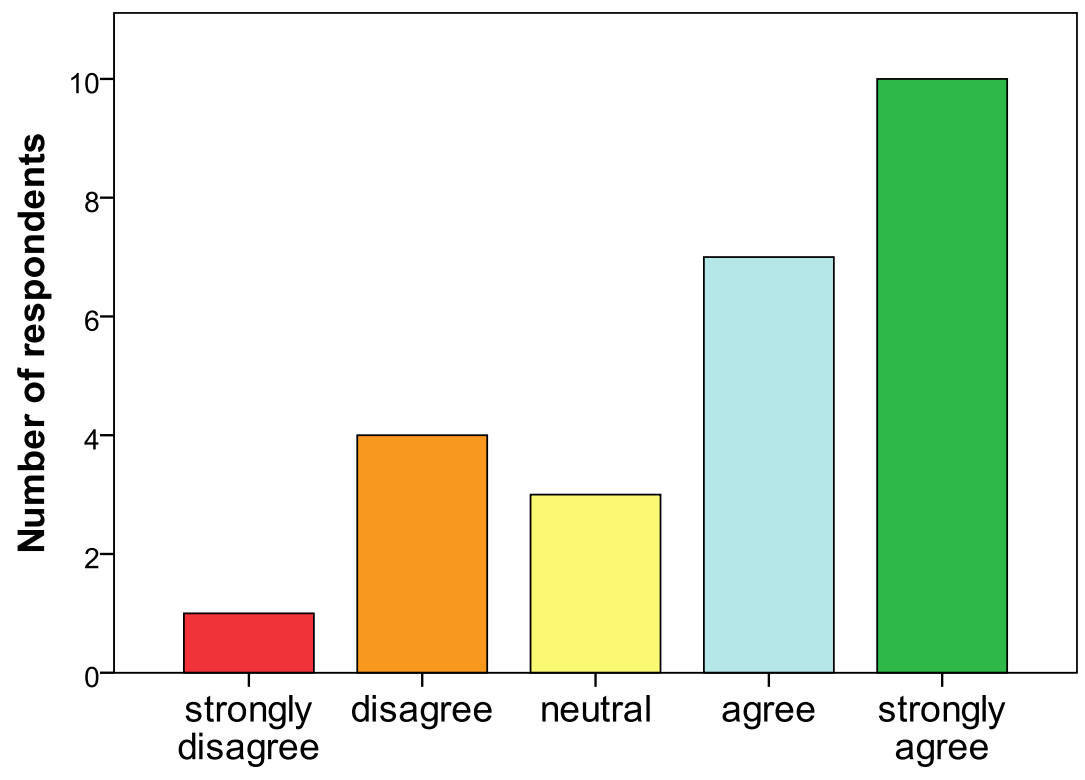

Given the choice, I would prefer to use the eOSCE system over paper-based marking forms.

Figure 4. Examiner $(\mathrm{n}=25)$ response about their preference for the eOSCE or a traditional paper-based OSCE 


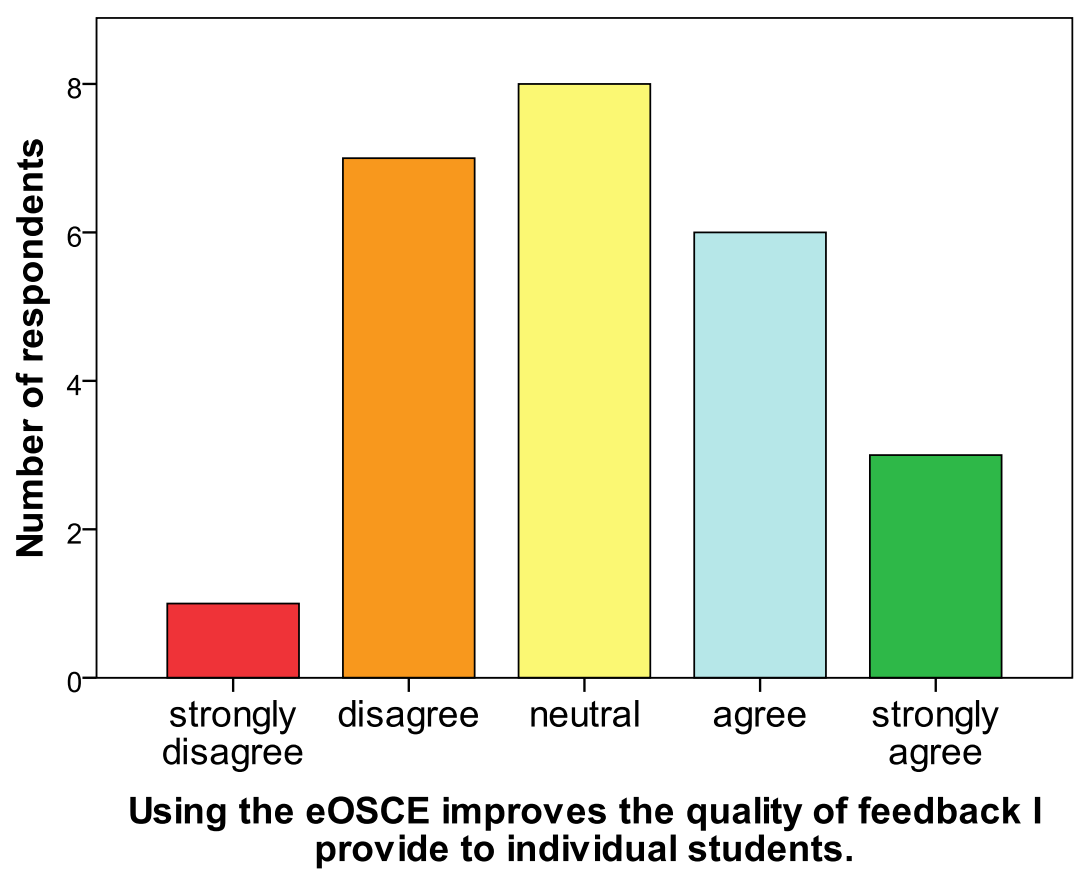

Figure 5. Examiner $(\mathrm{n}=25)$ response about the effect of the eOSCE on the quality of the feedback they provide

Examiners who preferred the eOSCE over traditional paper-based systems cited reasons such as its consistency of marking, its efficiency in providing automated rapid feedback to students, and the instant uploading of marks which reduced academic workload. Those examiners who preferred the paper-based system cited reasons that included being able to write faster than they could type on the iPad and believing that paper versions of marking forms were easier to complete. They also felt they could provide more specific feedback to students using paper forms. Examiners who agreed that the eOSCE improved the quality of student feedback reported that the automated feedback system ensured that each student received feedback and eliminated problems with illegible handwriting from examiners, improving the accuracy of feedback. They also thought that the ability to select standardised feedback statements made examiners more efficient. Of the examiners who responded that the eOSCE did not improve the quality of student feedback, some reported a lack of feedback specificity and others believed there were too many feedback options, potentially making it difficult to scroll through all the options to find the one they wanted.

Examiners responded to the open-ended questions and reported a variety of advantages and disadvantages of the eOSCE system as compared to traditional paper-based OSCEs. These are listed in Table 2. In summary, examiners thought the eOSCE was advantageous for student feedback because feedback was standardised, consistent, legible and automated. The disadvantages they reported with the eOSCE included losing eye contact with students while marking, standardised student feedback not covering each scenario they wanted to comment on, and general technical issues in using technology.

Examiners responded to the invitation for further open-ended comments on their experience by providing further suggestions for improving the eOSCE from their perspective as examiners. These recommendations and comments are summarised in Table 3. Their suggestions covered technical aspects of using the system, as well as recommendations for future examiners to better learn how to use the eOSCE prior to an examination. The recommendations they provided focussed on ways to make it easier for examiners to use the system for marking and providing student feedback. 
Table 2

Summary of open-ended responses from examiner questionnaires $(n=25)$ on the perceived advantages and disadvantages of the eOSCE system, grouped into commonly reported categories

\begin{tabular}{|c|c|c|}
\hline Category & Advantages & Disadvantages \\
\hline $\begin{array}{l}\text { Student } \\
\text { feedback }\end{array}$ & $\begin{array}{l}\text { Preloaded, standardised feedback } \\
\text { statements. } \\
\text { Immediate and automated student } \\
\text { feedback. } \\
\text { Legible feedback for students. } \\
\text { Consistent feedback across } \\
\text { examiners. }\end{array}$ & $\begin{array}{l}\text { Too many feedback options to scroll through } \\
\text { while marking. } \\
\text { Inferior quality of feedback statements } \\
\text { compared to handwritten feedback; too } \\
\text { generic. } \\
\text { Feedback statements did not cover every } \\
\text { scenario tested. }\end{array}$ \\
\hline $\begin{array}{l}\text { Mark-Rite } \\
\text { software }\end{array}$ & $\begin{array}{l}\text { Quick and easy to use. } \\
\text { Better marking scale compared to } \\
\text { writing on paper and summing by } \\
\text { hand. }\end{array}$ & $\begin{array}{l}\text { Problems with the system logging out in the } \\
\text { middle of the exam. } \\
\text { Reduced eye contact with the student because } \\
\text { focus was on using the iPad. } \\
\text { Cannot view the entire marking page at once } \\
\text { therefore requiring excessive scrolling. } \\
\text { Selection buttons on the iPad were too small. }\end{array}$ \\
\hline $\begin{array}{l}\text { Administrative } \\
\text { load }\end{array}$ & $\begin{array}{l}\text { Instant uploading of marks. } \\
\text { No paperwork for examiners post- } \\
\text { examination. }\end{array}$ & $\begin{array}{l}\text { Insufficient time for examiner to give } \\
\text { personalised feedback and finalise marking } \\
\text { before transitioning to next student. } \\
\text { eOSCE took longer than a traditional OSCE } \\
\text { to mark. }\end{array}$ \\
\hline iPad & $\begin{array}{l}\text { Portability of iPad enabled } \\
\text { mobility of examiner. }\end{array}$ & $\begin{array}{l}\text { iPads became heavy as the day progressed. } \\
\text { Very sensitive touch screen on the iPad made } \\
\text { the 'lock function' hard to use. } \\
\text { Difficult to type while holding the iPad. }\end{array}$ \\
\hline
\end{tabular}

*OSCE $=$ Objective Structured Clinical Examination; eOSCE = electronic Objective Structured Clinical Examination

\section{Course coordinator interviews}

The three course coordinators who used the eOSCE in their courses were interviewed. Two were from UoN: one undergraduate physiotherapy course coordinator and one undergraduate occupational therapy course coordinator. The one from UQ coordinated two entry-level physiotherapy courses, one with undergraduate students and one with graduate students. All course coordinators used the eOSCE with students in the second year of their programs.

Course coordinators found the eOSCE system to be user-friendly overall. This was despite having initial problems with the technology that included difficulty locking and unlocking Criteria due to unfamiliarity with the sensitivity of the iPad, and the system timing out (and logging them off) when there was no activity for a period of time. They reported the main advantage of the eOSCE was the automated student feedback, which was beneficial in three ways: (1) all students received feedback, regardless of their motivation to seek feedback; (2) immediate feedback was perceived as reassuring to students regarding their performance; and (3) it reduced the post-examination administrative workload. One course coordinator found the eOSCE reduced the overall workload in administering a practical examination "somewhere between 40 and $50 \%$ in the preparation of the exam". However, the other two course coordinators reported administering the eOSCE increased their workload compared to their traditional paper-based OSCE. 
Table 3

Recommendations from examiner questionnaires $(n=25)$ for improving the eOSCE

\begin{tabular}{|c|c|}
\hline Theme & Recommendation \\
\hline $\begin{array}{l}\text { Feedback } \\
\text { statements }\end{array}$ & $\begin{array}{l}\text { Minimise the list of feedback statements to make scrolling easier. } \\
\text { Ensure that feedback statements cover every aspect of the examination. } \\
\text { Add specificity to statements. } \\
\text { Allocate time for examiner to add personalised free-text comments if desired and } \\
\text { also to finalise marking before transitioning to next student. } \\
\text { Provide a free-text section for each examination Criterion (rather than just one } \\
\text { free text box at the bottom of the page) to allow for specific comment input. } \\
\text { Organise feedback statements better to minimise excess scrolling. }\end{array}$ \\
\hline $\begin{array}{l}\text { Mark-Rite } \\
\text { system }\end{array}$ & $\begin{array}{l}\text { Optimise software so that focus is mainly on student's performance rather than } \\
\text { technology/software. } \\
\text { Have one 'lock function' per student for the entire rather than for each section of } \\
\text { the exam. }\end{array}$ \\
\hline iPad & $\begin{array}{l}\text { Use in portrait view rather than landscape. } \\
\text { Use both hands to type rather than one finger. } \\
\text { More practice on using the touch function to determine sensitivity. }\end{array}$ \\
\hline $\begin{array}{l}\text { Examiner } \\
\text { training }\end{array}$ & $\begin{array}{l}\text { Have a training session closer to the examination period for examiners so that the } \\
\text { information is relatively fresh in their minds } \\
\text { Use the actual examination during the training session in order to identify } \\
\text { problems and fix them prior to the examination. } \\
\text { Identify what level of expertise examiners have with the technology and offer } \\
\text { additional sessions to increase confidence in using a new system. } \\
\text { Practice marking with a videotaped demonstration. } \\
\text { Ensure that every examiner is thoroughly familiar with the system, equipment } \\
\text { and process of the eOSCE. }\end{array}$ \\
\hline Other comments & $\begin{array}{l}\text { If an examiner wants to return to a particular student after an eOSCE to review } \\
\text { their mark, they should write down their name and the examination question they } \\
\text { answered in order to find them in the system again. }\end{array}$ \\
\hline
\end{tabular}

The disadvantages to using the eOSCE, as reported by course coordinators, were mainly regarding increased time in setting up an initial eOSCE and technical issues inherent in using new technology. Initial set up time included creating standardised feedback statements for use in the examination and programming these into the Mark-Rite ${ }^{\mathrm{TM}}$ system. Technical issues included examiner problems with logging in, keeping the iPads charged throughout a day of examining, lack of familiarity with the iPad touch screen causing some examiners to have trouble selecting and deselecting items, and upper limb fatigue from holding the weight of the iPad throughout a day of examining. One coordinator reported it would be difficult for examiners and coordinators to remember how to use the system efficiently, because in their courses OSCEs were only administered at six monthly intervals.

Course coordinators varied in their opinion about whether they preferred the eOSCE over a traditional OSCE. One of the three course coordinators preferred a paper-based system over the eOSCE, primarily in order to have notes at hand when students requested additional feedback rather than having to download students' feedback from the Mark-Rite ${ }^{\mathrm{TM}}$ system, but also due to a preference for paper over technology during OSCE marking. Another of the course coordinators was apprehensive about the technology with a fear of lost data and of mechanical failure, but felt that with "a little more faith that nothing was going to go wrong, [the course coordinator] would choose the iPad system" over the paper-based. The third course coordinator preferred the eOSCE due to the administrative time saving over their traditional OSCE.

Course coordinators provided a range of suggestions to improve the eOSCE system. All course coordinators recommended refining and improving their feedback statements to make them more specific and more closely reflect the skills examined. They suggested the free text feedback provided by examiners could be reviewed to assist in developing more specific statements in the future. They also recommended that the eOSCE form visible on the iPad be further improved to minimise scrolling during an examination. They suggested that the training of examiners should occur close to the date of an 
examination, and that the examination to be used for the eOSCE also should be used for training so that examiners could practice using the actual questions and feedback statements to be used in their examination.

\section{Course coordinator logbooks}

Only one course coordinator completed and returned a logbook. This course coordinator had conducted a paper-based OSCE, as well as two eOSCEs. They documented the hours spent on tasks related to each examination. For the paper-based OSCE, they spent a total of 8 hours preparing for the OSCE (designing examiners' forms, student tasks and an answer key, plus scheduling), 3 hours collating marks after the OSCE, and 4 hours meeting with students for feedback. For the eOSCE, they spent 4 hours preparing (designing student tasks and scheduling), 2 hours collating marks and 2 hours meeting with students for feedback.

\section{Discussion}

An eOSCE was implemented in four second year health courses (in physiotherapy and occupational therapy) at two universities. Examiners using the eOSCE found the electronic system easy to use and most preferred it over a traditional paper-based system, but there were mixed opinions as to whether it improved the quality of the feedback provided. Course coordinators found that the eOSCE provided equity by ensuring all students received feedback, but differed in their views as to whether it saved administrative time. Overall, the majority of educators felt that with continued improvements to both their examination design and the eOSCE online system, the eOSCE would be superior to traditional OSCE methods because of the provision of feedback to all students and time savings in OSCE administration.

This is the first published study identified that used iPads to administer an OSCE. Several studies have reported benefits from using a PDA to administer an OSCE, which include improved reliability in marking (Palen et al., 2008), time savings for OSCE administration (Treadwell, 2006; Van Schoor et al., 2006), and the ability to quickly send feedback to students following an OSCE (Van Schoor et al., 2006). The iPad system used in the current eOSCE also potentially has these benefits but in addition it addresses one problem reported with using PDAs which is the size of the visual field seen while examining (Kneebone, Nestel, Ratnasothy, Kidd, \& Darzi, 2003).

\section{Challenges with implementation}

The main challenge to implementation was a general distrust of technology by academics. This agrees with previous research that noted the need for training to allow academics to become familiar with new technology prior to its implementation in examinations (Pinto et al., 2008). The findings from the current study indicated that the use of technology was associated with concerns about the reliability of "the system" and apprehension about losing data, selection of the correct student, saving and storing the correct data for each student, and about the potential for the system to shut down during an examination. However, our findings following trialling the new technology in eight exams in four settings, found that most of these fears were unfounded. This confirms the importance of extensive trials to ascertain the functionality of new systems to reassure examiners (Torre, Treat, Durning, \& Elnicki, 2011). The eOSCE system proved robust and no data were lost.

Another challenge to implementation of the eOSCE in the current study was the academic time needed to develop the standardised feedback statements to be used in the eOSCE (Dearnley et al., 2009; Renaud \& Jalali, 2011). It is important that in the implementation of any new system that there is a recognition of the pressures of academic workload. In the current study the time pressures for academics were highlighted in the time needed to develop meaningful feedback statements that could be easily understood by students. This was time consuming because course coordinators and examiners had not previously used standardised feedback when marking on paper forms. Thus, it was a challenge to write feedback in a form that would be clear to the students when receiving it as a statement in an email. In one course, feedback statements were developed by consensus among examiners and achieving agreement between examiners was difficult. In another course, feedback statements were developed by a single person and circulated to examiners for comment. Examiners did not take the time to comment on the statements prior to the eOSCE but then reported after the examination that the statements were not specific enough for the 
comments they wanted to make. Though examiners could review an examination online prior to the examination, this was rarely done and examiners struggled with efficiently and quickly selecting feedback statements. They were not familiar with finding the feedback statement they wanted in the eOSCE form, though they were organised in a logical manner. This finding highlighted that in addition to the development of feedback it is equally important that its delivery is well structured (Gijbels, Coertjens, Vanthournout, Struyf, \& Van Petegram, 2009).

\section{Advantages and disadvantages of the eOSCE}

The advantages of the eOSCE, as reported by participants in our surveys, were the immediate feedback provided to students and the standardised feedback statements which made providing feedback easier and more legible for students. Students are known to prefer timely feedback which focuses on improving future performance in similar assignments (Boud \& Falchikov, 2006). Furthermore, the eOSCE provides more flexibility in scoring, as marks are tallied electronically. For example, a paper-based marking schema might have a Criterion worth $20 \%$, or two points out of ten, and an examiner may give a student a score of 1 or 1.5 for that Criterion. However, the eOSCE can be designed to allow scoring for that Criterion out of ten points and then assign a weighting of $20 \%$ to the Criterion score. This provides a greater spread of scoring over each Criterion. It is acknowledged that it is possible to design a paper form using a wide spread of marks the same as the eOSCE, however in practice this is rarely done. Examiners also cited the portability of the iPad as an advantage, enabling mobility of the examiner as compared to online marking on a laptop.

The disadvantages of the eOSCE as reported in our study were primarily related to (1) the design of the examination, and (2) characteristics inherent in the technology. Using a different examination design, many of the reported disadvantages could be remedied. For example, examiners felt the standardised feedback statements were inferior to handwritten feedback and did not cover every scenario tested. Further development of the feedback statements for each examination in consultation with examiners would be needed to improve the feedback statements. Examiners also reported more time was needed within the examination to allow for providing student feedback with the iPads, and this could be remedied with scheduling. Additional practice with the iPad may enable examiners to achieve greater eye contact with students during an eOSCE. Examiners reported that the number of feedback statements made it difficult to mark, as it required excessive scrolling to go through all the options, and some reported the selection buttons were too small. Conversely, they also reported they wanted additional feedback statements. When designing an eOSCE, course coordinators should seek to achieve a balance between the number and specificity of feedback statements and the quantity of statements possible to be viewed on the iPad screen at one time. Furthermore, making the selection buttons larger would mean that fewer feedback statements would be visible at one time, so a balance is required. Though examiners reported the eOSCE took longer to mark than a conventional OSCE, the additional feedback that students receive after the eOSCE may provide a benefit that is worth using a little additional marking time.

Disadvantages that were reported related to the technology could be addressed by examiners having more familiarity and more practice with the iPad. For example, examiners had trouble with the "locking" function used in the eOSCE when they were not used to the level of sensitivity required when making selections on an iPad, and they found it difficult to type in free-text comments as quickly as they would like. Problems with the system logging out could be remedied by setting a longer period of inactivity before the system logs out a user. Security of data must be considered when determining the length of time of inactivity prior to log out, but this can be determined on the basis of the security of the iPads in an examination setting. Examiners reported the iPads became heavy throughout a day of marking, so it is important to provide a place for examiners to set down their iPad where it cannot be viewed by students completing an examination.

\section{Limitations}

These results are limited to the experiences and views of educators in two allied health disciplines at two universities in Australia, and the results reflect the perceptions of the individuals participating in the eOSCEs at the time of these trials. However, the eOSCE was trialled in both physiotherapy and occupational therapy programs and with both undergraduate and graduate students, improving the generalisability of the results. The eOSCE system used in this trial (Mark-Rite ${ }^{\mathrm{TM}}$ ) was very new, and 
adjustments to improve the system were made as subsequent eOSCEs occurred. Many of the difficulties we encountered with the eOSCE will be able to be resolved in future by improving the training of users of the eOSCE.

\section{Future research}

The eOSCE has the potential to be utilised by any professional discipline that assesses students' practical skills using multiple examiners and stations. However, it is unknown how effective it might be in assessing the skills needed by other health and non-health professions, so future research to evaluate its use in additional discipline programs is required. One of the challenges for the effectiveness of the eOSCE in this study was the disparity between the standardised feedback statements used in the examinations and the feedback that examiners wanted to provide to students. Future development of standardised feedback statements within each professional discipline is required. In addition, the development of strategies to encourage the involvement of examiners in developing feedback statements prior to an eOSCE would be beneficial in improving the specificity of feedback. Lastly, the eOSCE has potential mechanisms (such as possible additional download formats for spreadsheets of student marks and compatibility with web learning software such as Blackboard) that may further reduce the administrative burden on academic course coordinators, and future investigation is needed to determine if further reductions in the academic administrative burden are possible while preserving the student benefits of the eOSCE system.

\section{Recommendations for educators}

When implementing an eOSCE, it is important to first reassure academics of the robustness of the system and let them spend enough time becoming familiar with the system so they are comfortable. Instruct course coordinators to allow enough lead time in preparation for their first eOSCE to develop clear and meaningful feedback statements. Hold examiner training within a week of an eOSCE and let examiners practice on the iPads using the eOSCE material that they will see during their examination. Encourage examiners to think about the types of feedback they are likely to provide and adjust the feedback statements accordingly. Use a video-taped or real-time mock exam during training to allow examiners to experience what it is like to use the system when their time is limited. For a first eOSCE, it is likely that some additional examination time may initially be required in order for examiners to provide the individualised student feedback, so course coordinators should allow for this with scheduling. Lastly, as with any change involving new technology, it is important to have a "champion" of the new system embedded within the academic faculty of the professional discipline in which the eOSCE is implemented.

\section{Conclusion}

The eOSCE is an innovative mechanism for examining practical skills. Its advantage is that it provides immediate individualised feedback for students, providing feedback while a student is still focussed on their performance and improving equity in feedback among students. The challenge to implementing an eOSCE is ensuring all examiners and course coordinators are comfortable with the technology.

\section{Acknowledgements}

Support for this publication has been provided by the Australian Government Office for Learning and Teaching (Grant Ref.: PP10-1628). The views expressed in this publication/activity do not necessarily reflect the views of the Australian Government Office for Learning and Teaching. The researchers wish to thank the examiners and course coordinators for their participation in this study.

\section{Conflict of interest}

T. Russell has a financial interest in Mark-rite ${ }^{\mathrm{TM}}$ (Clarity data Solutions, Brisbane, Australia), which was the software used for the eOSCEs investigated in this research, creating a possible conflict of interest. Every effort has been made by the authors to report the facts regarding the research reported herein without bias. 


\section{References}

Bhatt, V. R., Giri, S., \& Koirala, S. (2010). Health workforce shortage: A global crisis. The Internet Journal of World Health and Societal Politics, 7(1).

Boud, D., \& Falchikov, N. (2006). Aligning assessment with long-term learning. Assessment \& Evaluation in Higher Education, 31(4), 399-413.

Dearnley, C., Taylor, J., Hennessy, S., Parks, M., Coates, C., Haigh, J., Fairhall, J., Riley, K., \& Dransfield, M. (2009). Using mobile technologies for assessment and learning in practice settings: Outcomes of five case studies. International Journal on E-Learning, 8(2), 193-207.

Fields, H. W., Rowland, M. L., Vig, K. W., \& Huja, S. S. (2007). Objective structured clinical examination use in advanced orthodontic dental education. American Journal of Orthodontics and Dentofacial Orthopedics, 131(5), 656-663.

Gijbels, D., Coertjens, L., Vanthournout, G., Struyf, E., \& Van Petegram, P. (2009). Changing students' approaches to learning: A two-year study within a university teacher training course. Educational Studies, 35(5), 503-513.

Hawker, J. A., Walker, K. Z., Barrington, V., \& Andrianopoulos, N. (2010). Measuring the success of an objective structured clinical examination for dietetic students. Journal of Human Nutrition and Dietetics, 23(3), 212-216.

Health Workforce Australia. (2011). National Health Workforce Innovation and Reform Strategic Framework for Action 2011-2015. (978-0-9871920-0-4). Adelaide: Health Workforce Australia Retrieved from http://www.hwa.gov.au/sites/uploads/hwa-wir-strategic-framework-for-action201110.pdf

Kneebone, R., Nestel, D., Ratnasothy, J., Kidd, J., \& Darzi, A. (2003). The use of handheld computers in scenario-based procedural assessments. Medical Teacher, 25(6), 632-642.

McIlroy, J. H. (2000). The impact of an alternative approach to computing station cut scores in an OSCE. Academic Medicine, 75(10 Suppl), S18-20.

Nackman, G. B., Griggs, M., \& Galt, J. (2006). Implementation of a novel web-based objective structured clinical evaluation. Surgery, 140, 206-211.

Palen, L. A., Graham, J. W., Smith, E. A., Caldwell, L. L., Mathews, C., Flisher, A. J., Palen, L.-A., Graham, J. W., Smith, E. A., Caldwell, L. L., Mathews, C., \& Flisher, A. J. (2008). Rates of missing responses in personal digital assistant (PDA) versus paper assessments. Evaluation Review, 32(3), 257-272.

Pinto, A., Selvaggi, S., Sicignano, G., Vollono, E., Iervolino, L., Amato, F., Molinari, A., \& Grassi, R. (2008). E-learning tools for education: regulatory aspects, current applications in radiology and future prospects. La radiologica medica, 113(1), 144-157.

Renaud, G., \& Jalali, A. (2011). Helping dyslexic medical students pass their OSCE exams. elearn magazine, 1-3.

Ross, M., Carroll, G., Knight, J., Chamberlain, M., Fothergill-Bourbonnais, F., \& Linton, J. (1988). Using the OSCE to measure clinical skills performance in nursing. Journal of Advanced Nursing, 13, 45-56.

Rushforth, H. E. (2007). Objective structured clinical examination (OSCE): Review of literature and implications for nursing education. Nurse Education Today, 27(5), 481-490.

Saldana, J. (2009). The coding manual for qualitative researchers. Thousand Oaks, California, US: SAGE Publications Ltd. 
Schmidts, M. B. (2000). OSCE logistics - Handheld computers replace checklists and provide automated feedback. [Short Survey]. Medical Education, 34(11), 957-958.

Sturpe, D. A. (2010). Objective structured clinical examinations in doctor of pharmacy programs in the United States. The American Journal of Pharmaceutical Education, 74(8), 148.

Torre, D. M., Treat, R., Durning, S., \& Elnicki, D. M. (2011). Comparing PDA- and paper-based evaluation of the clinical skills of third-year students. Wisconsin Medical Journal, 110(1), 9-13.

Treadwell, I. (2006). The usability of personal digital assistants (PDAs) for assessment of practical performance. Medical Education, 40(9), 855-861.

Turner, J. L., \& Dankoski, M. E. (2008). Objective structured clinical exams: a critical review. Family Medicine, 40(8), 574-578.

van den Berk, I. A., van de Ridder, J. M., \& van Schaik, J. P. (2011). Radiology as part of an objective structured clinical examination on clinical skills. European Journal of Radiololgy, 78(3), 363-367.

Van Schoor, A. N., Navsa, N., Meiring, J. H., Treadwell, I., Bosman, M. C., \& Greyling, L. M. (2006). Perspectives on the use of PDAs as assessment tools. Clinical Teacher, 3(3), 170-174.

Wilkinson, T. J., Frampton, C. M., Thompson-Fawcett, M., \& Egan, T. (2003). Objectivity in objective structured clinical examinations: Checklists are no substitute for examiner commitment. Academic Medicine, 78(2), 219-223.

Yuen, S. C.-Y., \& Yuen, P. K. (2003). PDAs as educational power tools. Tech Directions, 62(9), 14.

Corresponding author: Suzanne Snodgrass, Suzanne.Snodgrass@newcastle.edu.au.

Australasian Journal of Educational Technology (C 2014.

Please cite as: Snodgrass, S. J., Russell, T., Ashby, S. E., \& Rivett, D. A. (2014). Implementation of an electronic Objective Structured Clinical Exam for assessing practical skills in pre-professional physiotherapy and occupational therapy programs: Examiner and course coordinator perspectives. Australasian Journal of Educational Technology, 30(2), 152-166. 